Supplement of Nat. Hazards Earth Syst. Sci., 19, 611-628, 2019

https://doi.org/10.5194/nhess-19-611-2019-supplement

(C) Author(s) 2019. This work is distributed under

the Creative Commons Attribution 4.0 License.

(c) (1)

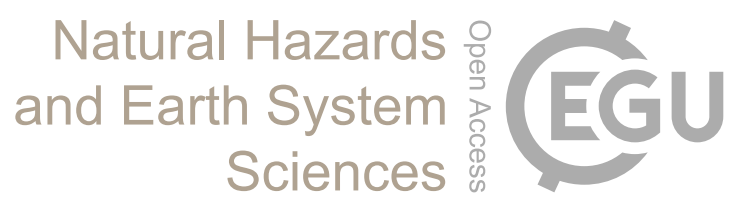

Supplement of

\title{
High-spatial-resolution probability maps of drought duration and magnitude across Spain
}

Fernando Domínguez-Castro et al.

Correspondence to: Fernando Domínguez-Castro (f.dominguez.castro@gmail.com)

The copyright of individual parts of the supplement might differ from the CC BY 4.0 License. 

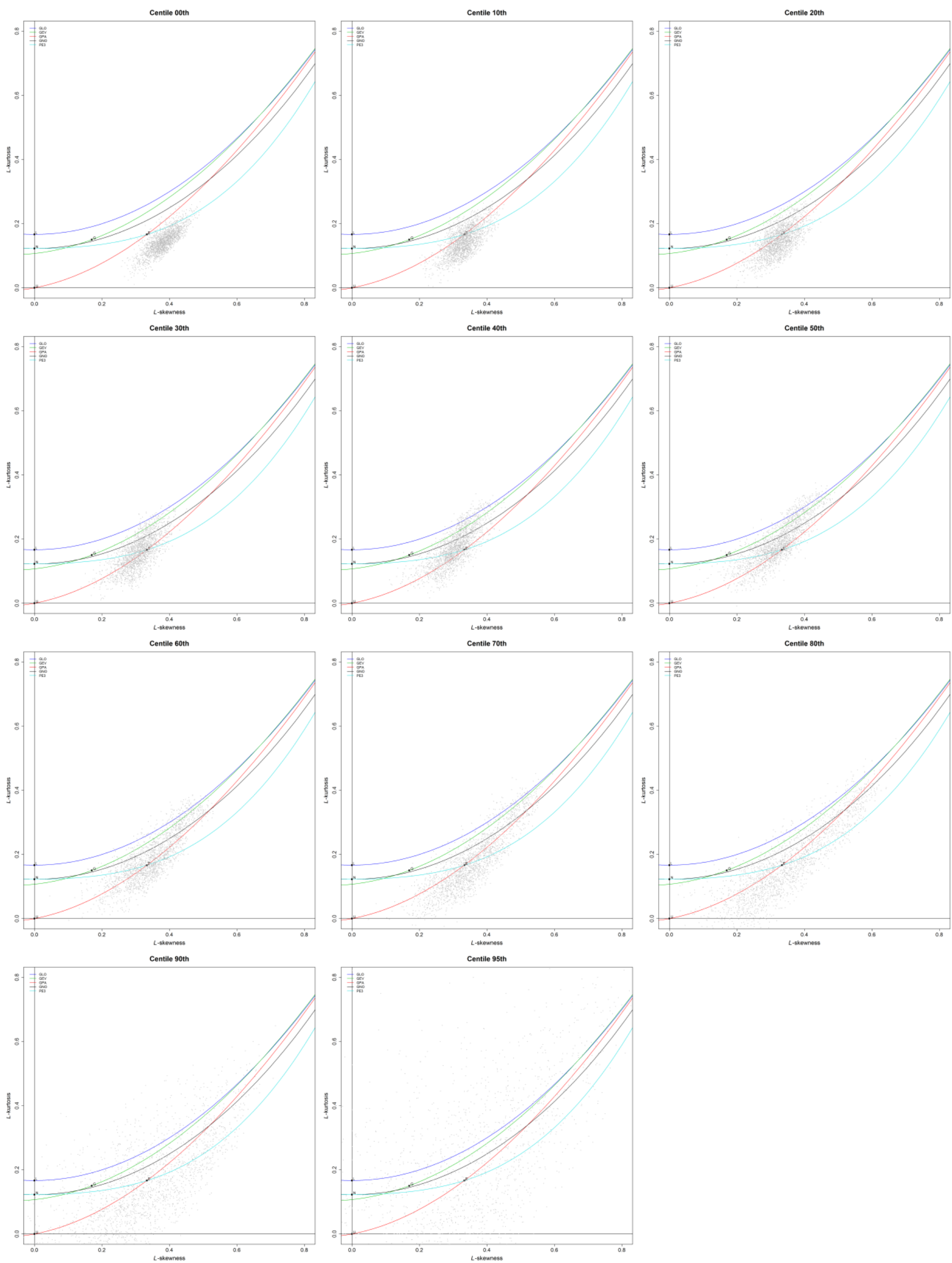

Supplementary Figure 1: L-moment diagrams for the peak-over-threshold series obtained from the 3-month SPEI duration series 

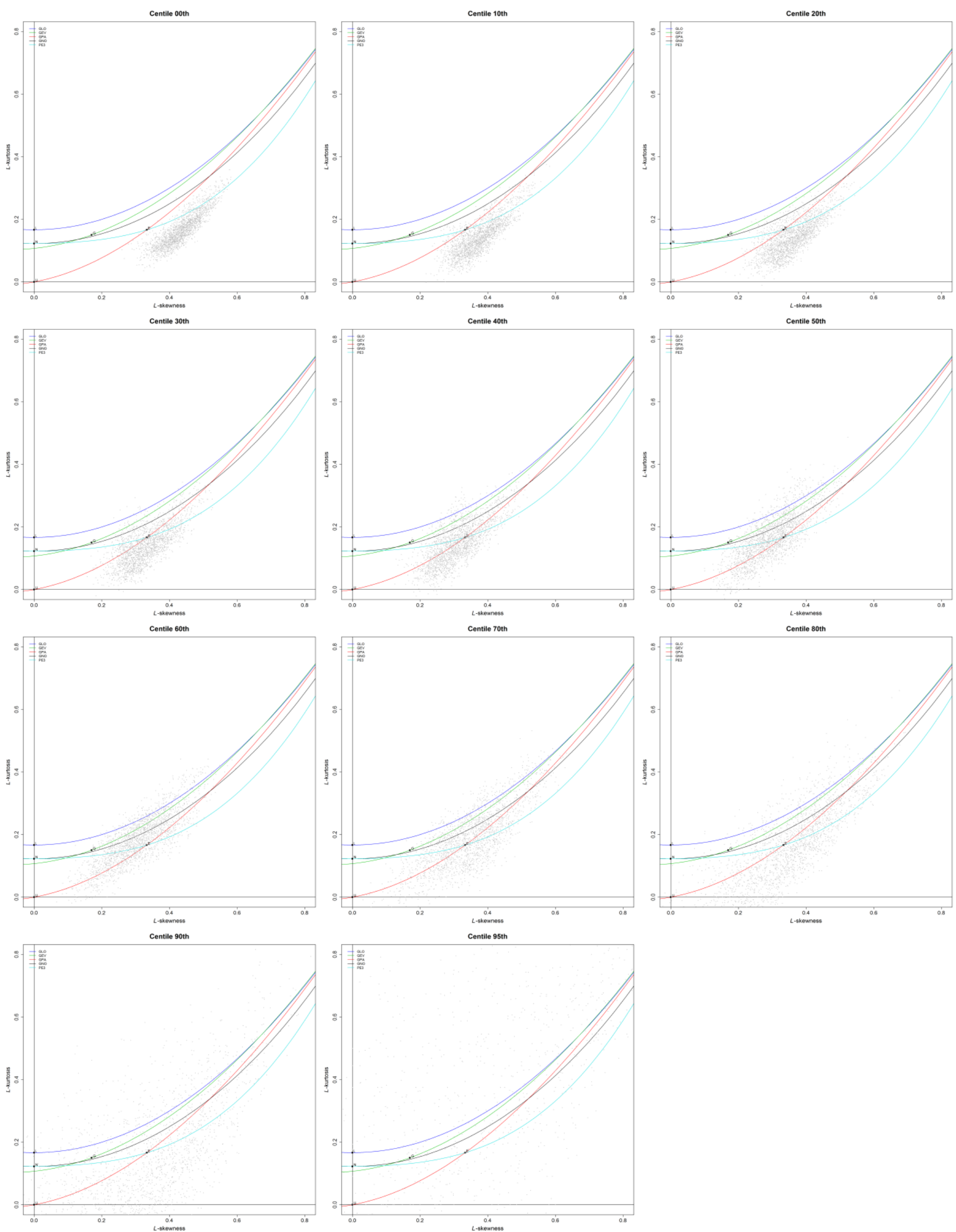

Supplementary Figure 2: L-moment diagrams for the peak-over-threshold series obtained from the 6-month SPEI duration series 

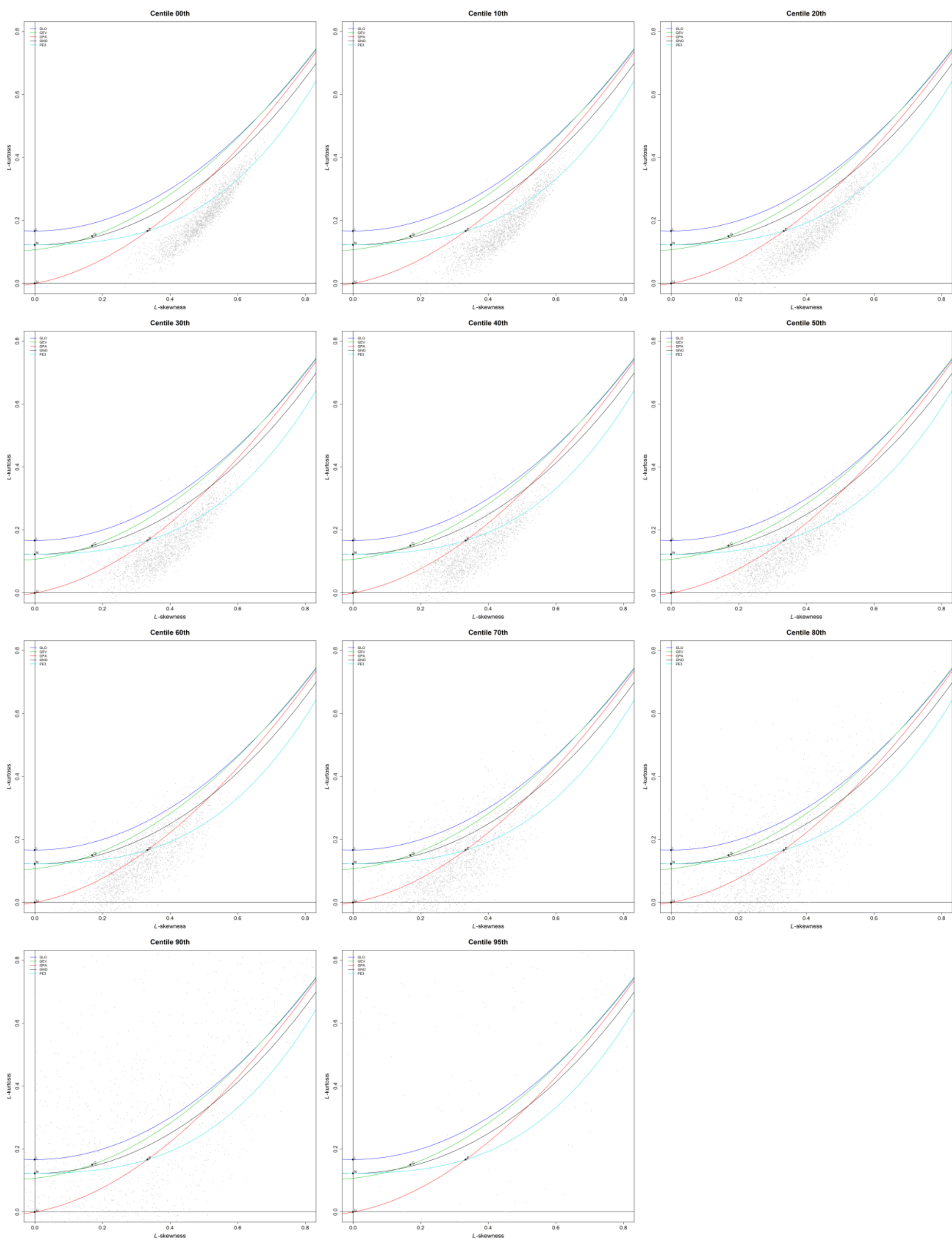

Supplementary Figure 3: L-moment diagrams for the peak-over-threshold series obtained from the 12-month SPEI duration series 

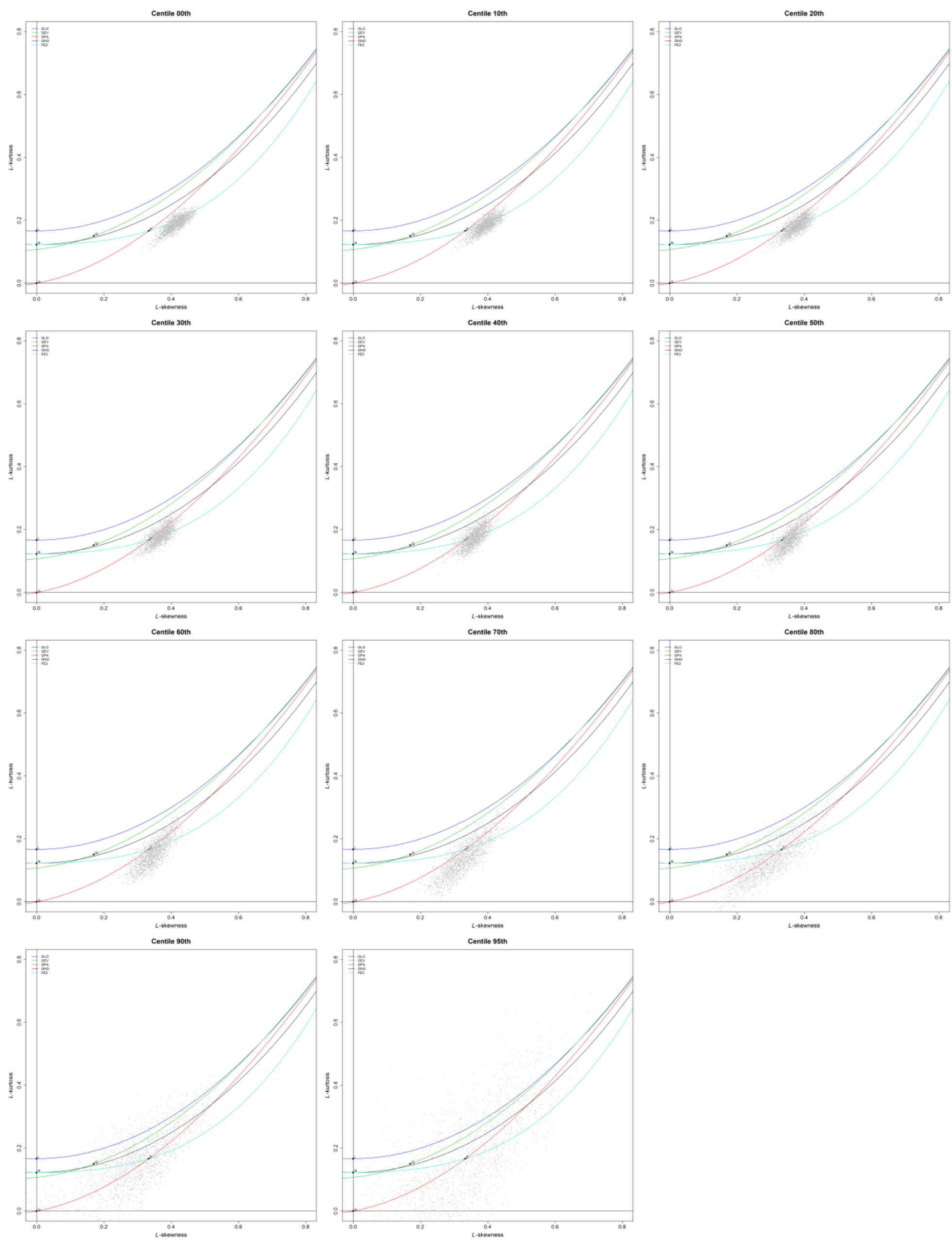

Supplementary Figure 4: L-moment diagrams for the peak-over-threshold series obtained from the 1-month SPEI magnitude series 

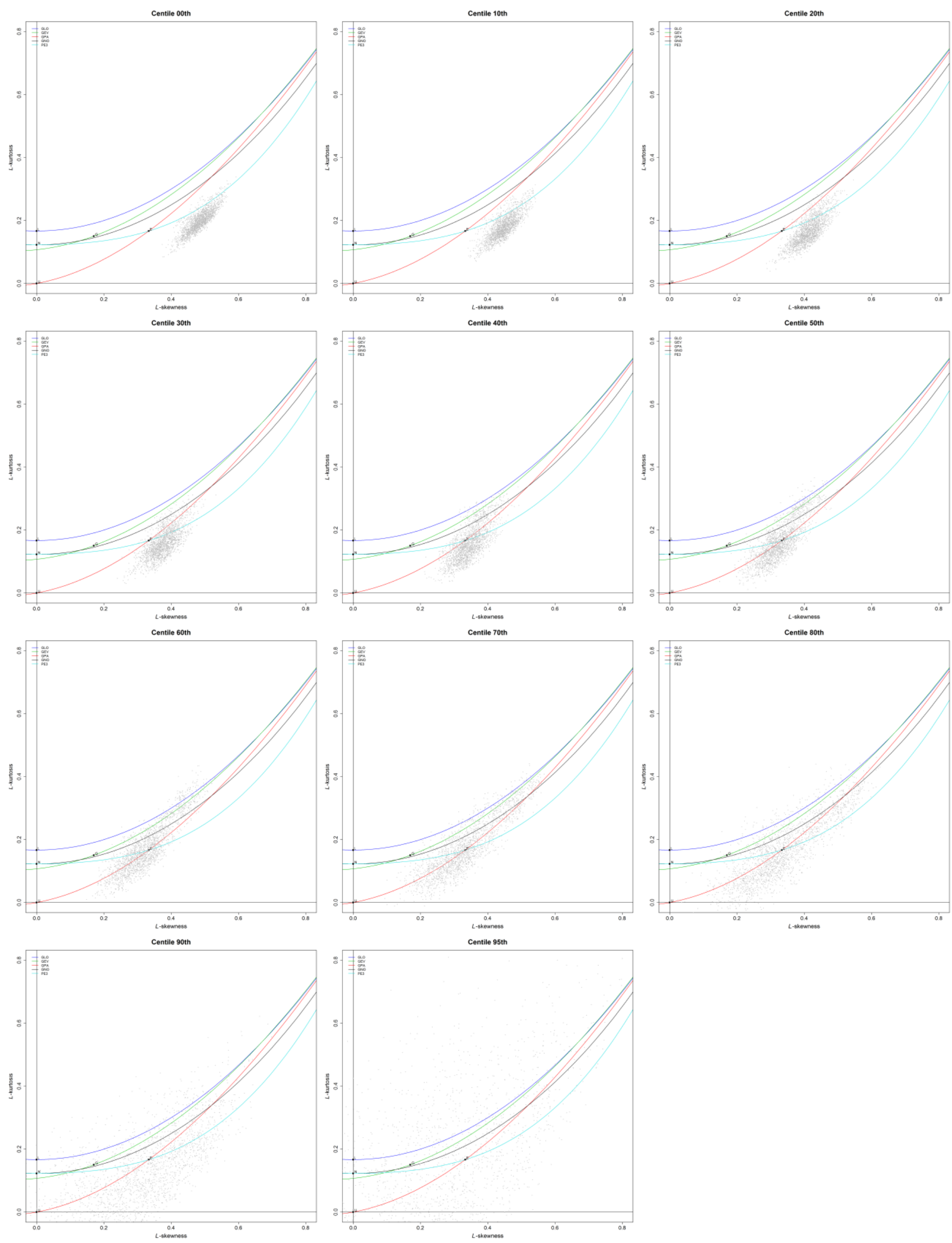

Supplementary Figure 5: L-moment diagrams for the peak-over-threshold series obtained from the 3-month SPEI magnitude series 

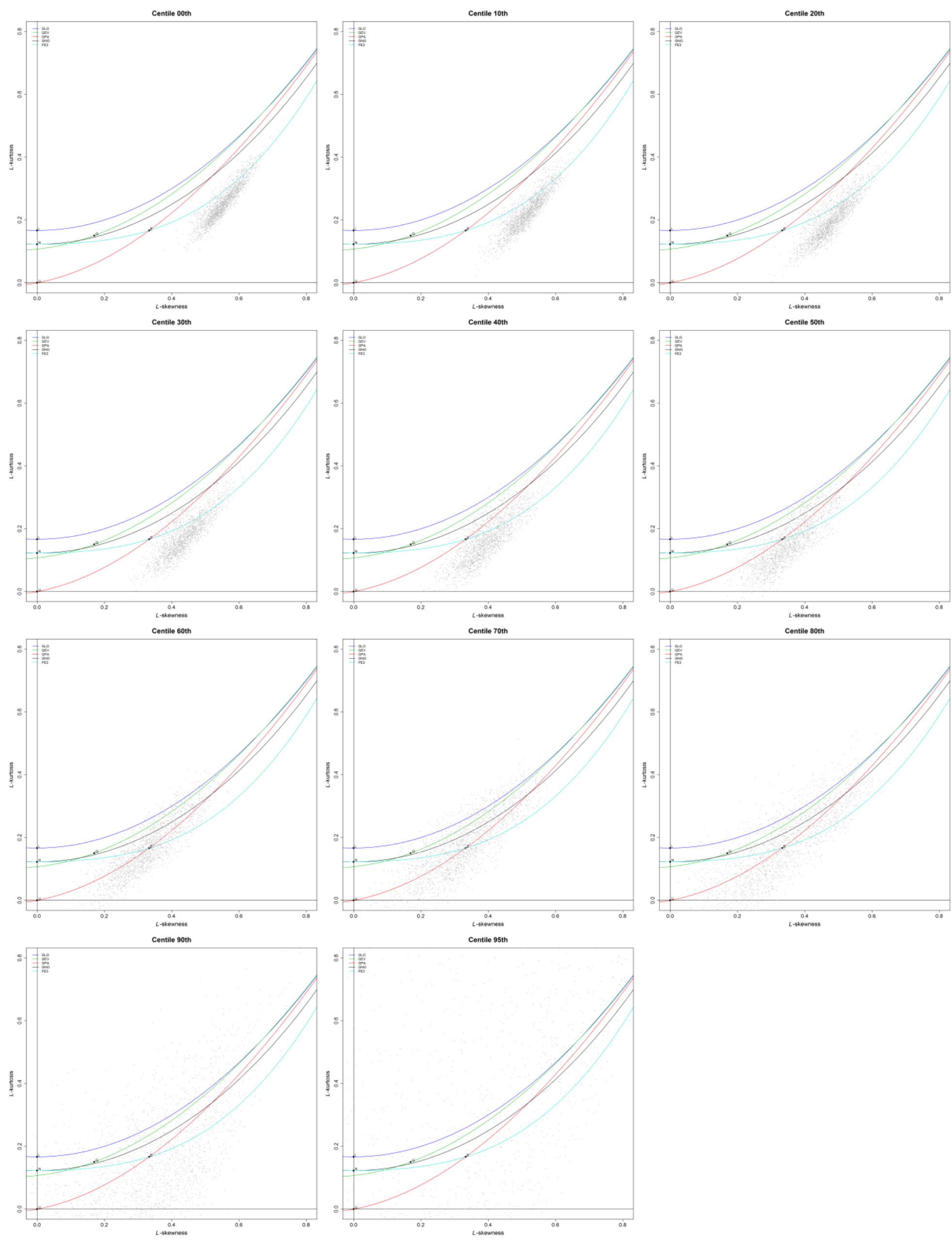

Supplementary Figure 6: L-moment diagrams for the peak-over-threshold series obtained from the 6-month SPEI magnitude series 

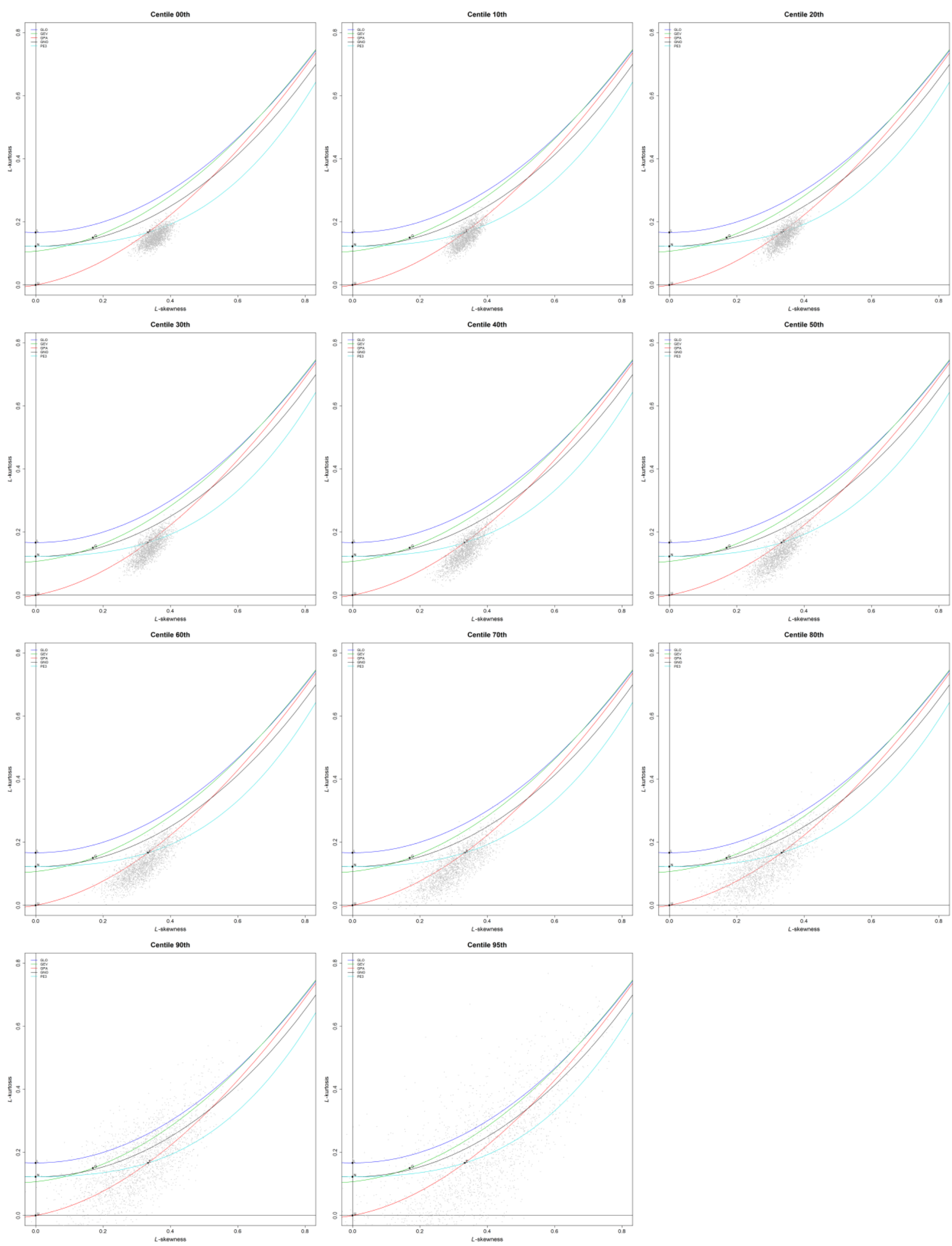

Supplementary Figure 7: L-moment diagrams for the peak-over-threshold series obtained from the 1-month SPI duration series 

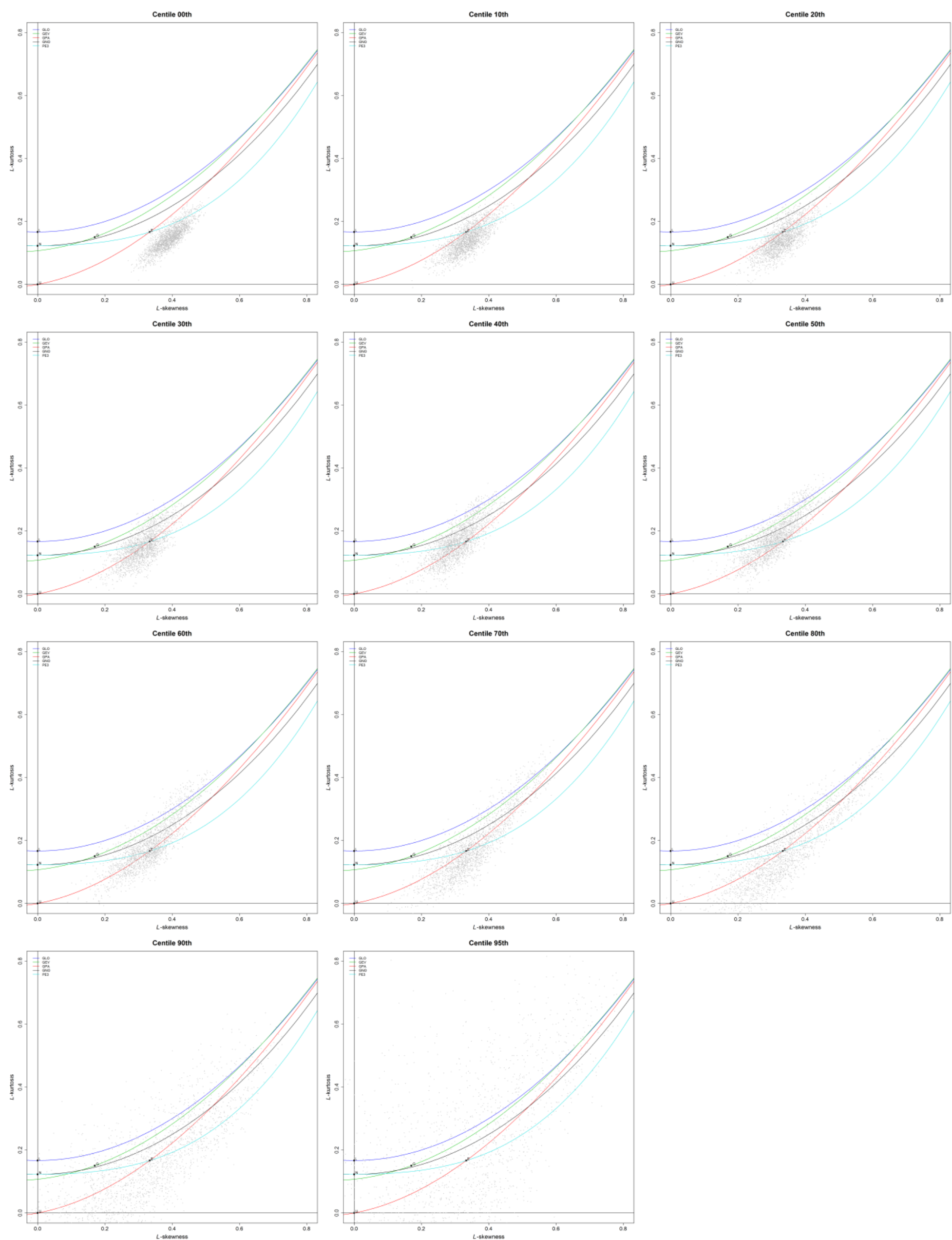

Supplementary Figure 8: L-moment diagrams for the peak-over-threshold series obtained from the 3-month SPI duration series 

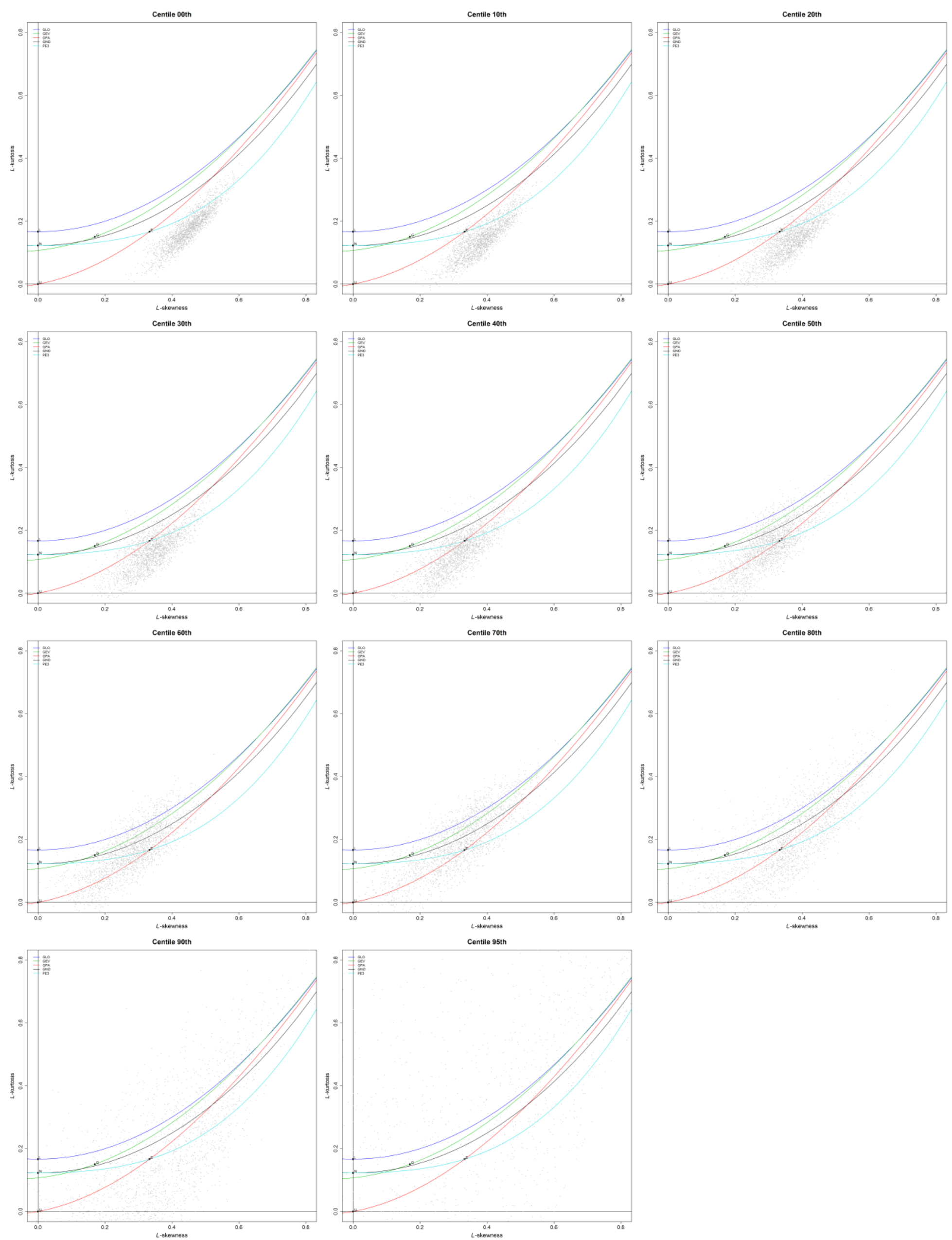

Supplementary Figure 9: L-moment diagrams for the peak-over-threshold series obtained from the 6-month SPI duration series 

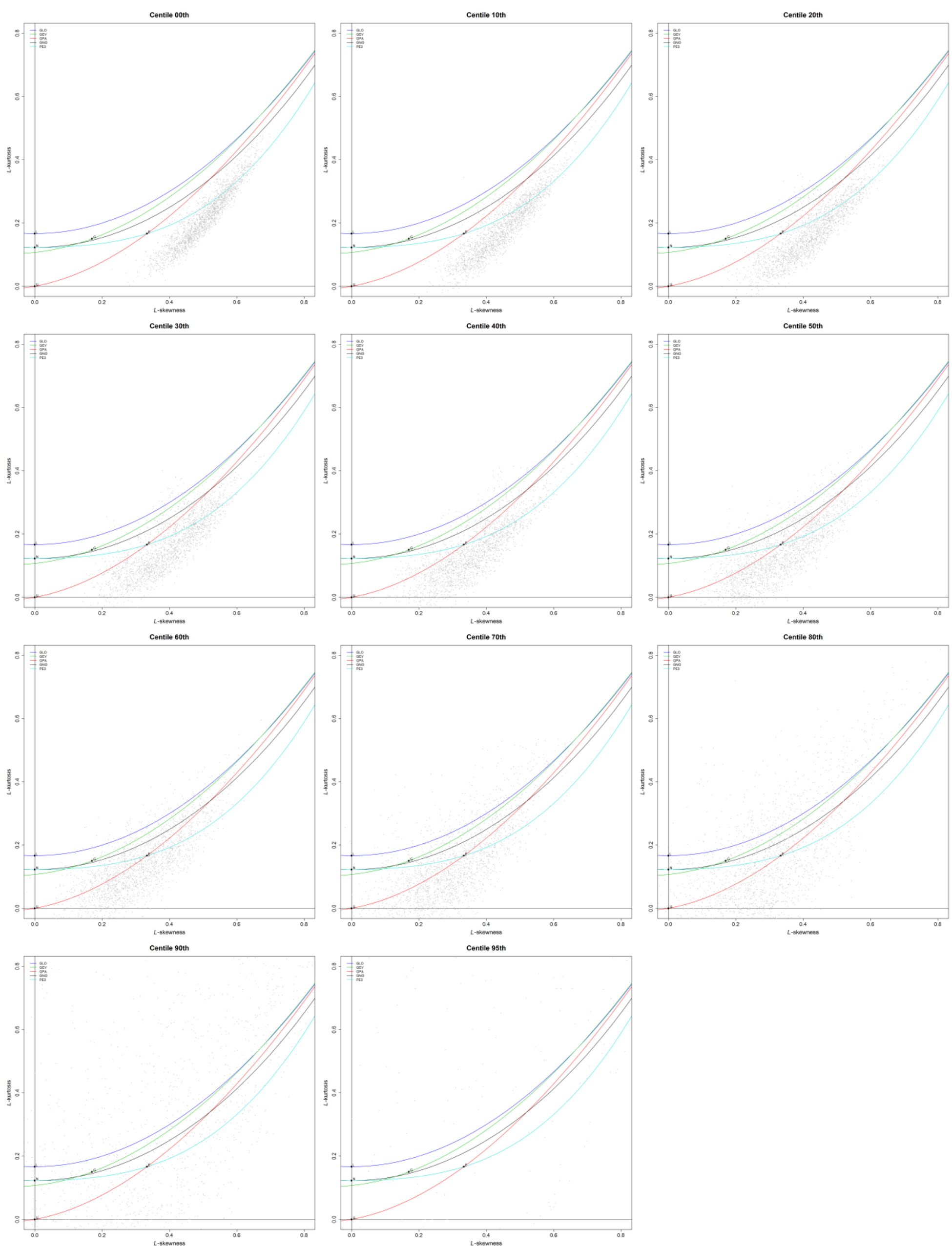

Supplementary Figure 10: L-moment diagrams for the peak-over-threshold series obtained from the 12-month SPI duration series 

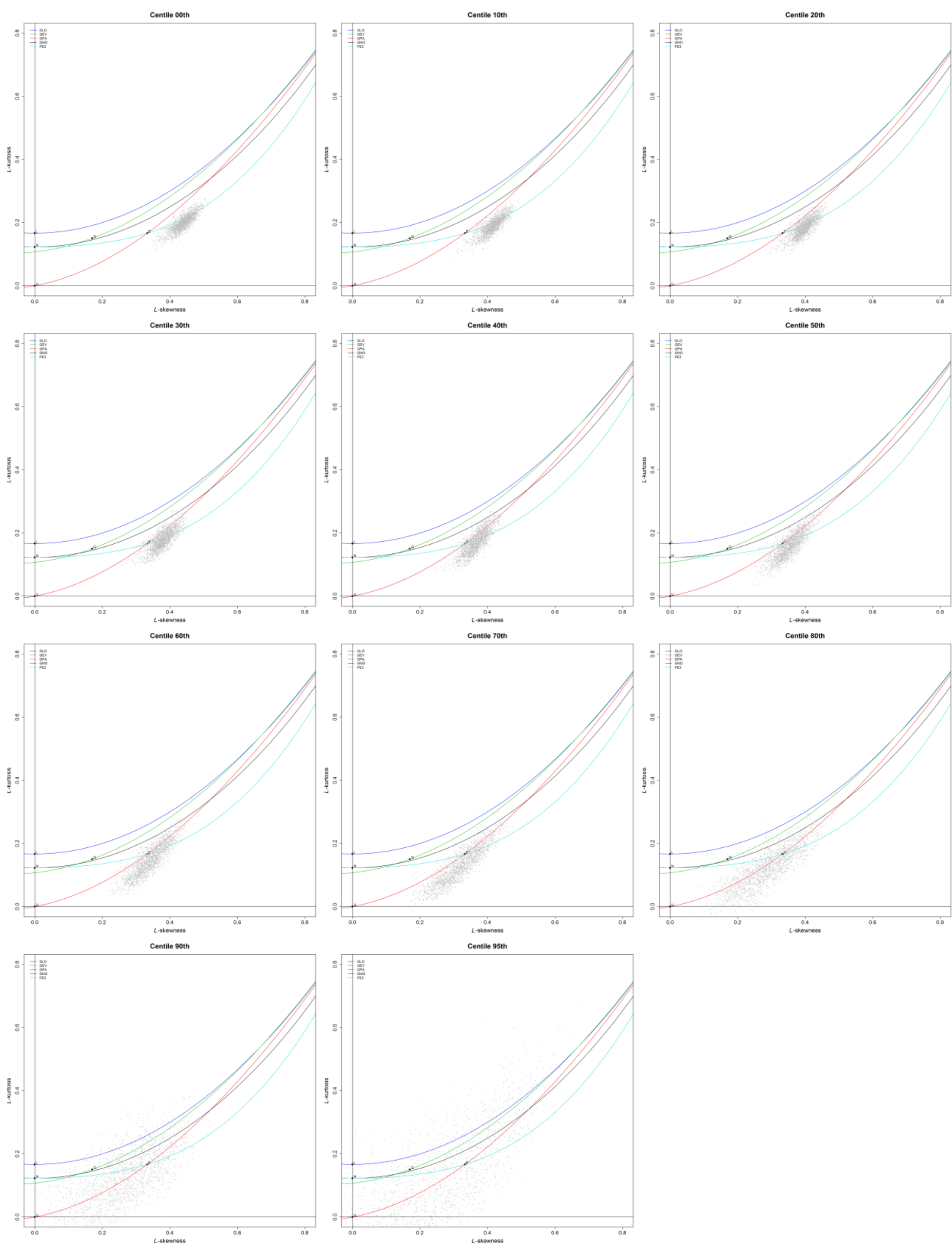

Supplementary Figure 11: L-moment diagrams for the peak-over-threshold series obtained from the 1-month SPI magnitude series 

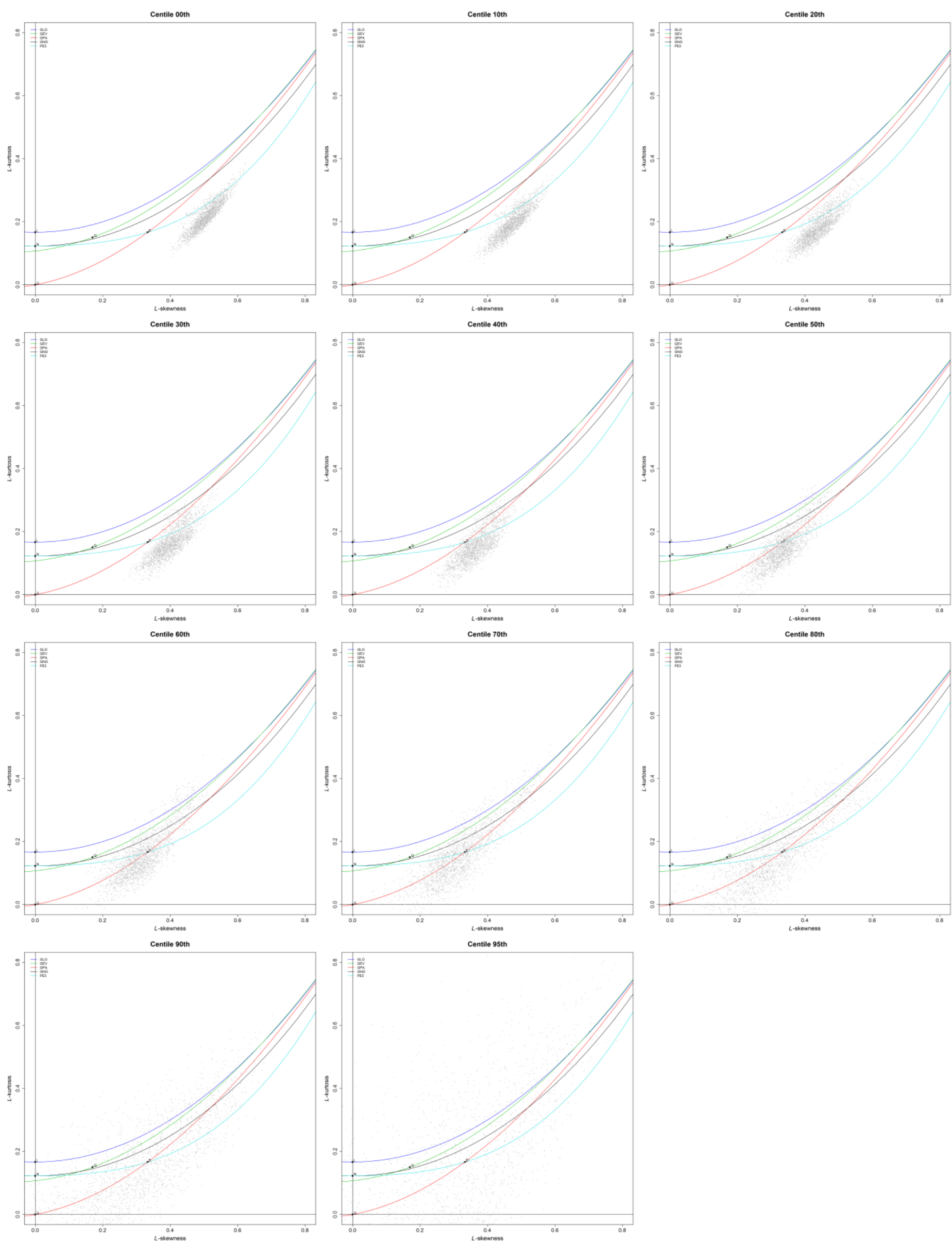

Supplementary Figure 12: L-moment diagrams for the peak-over-threshold series obtained from the 3-month SPI magnitude series 

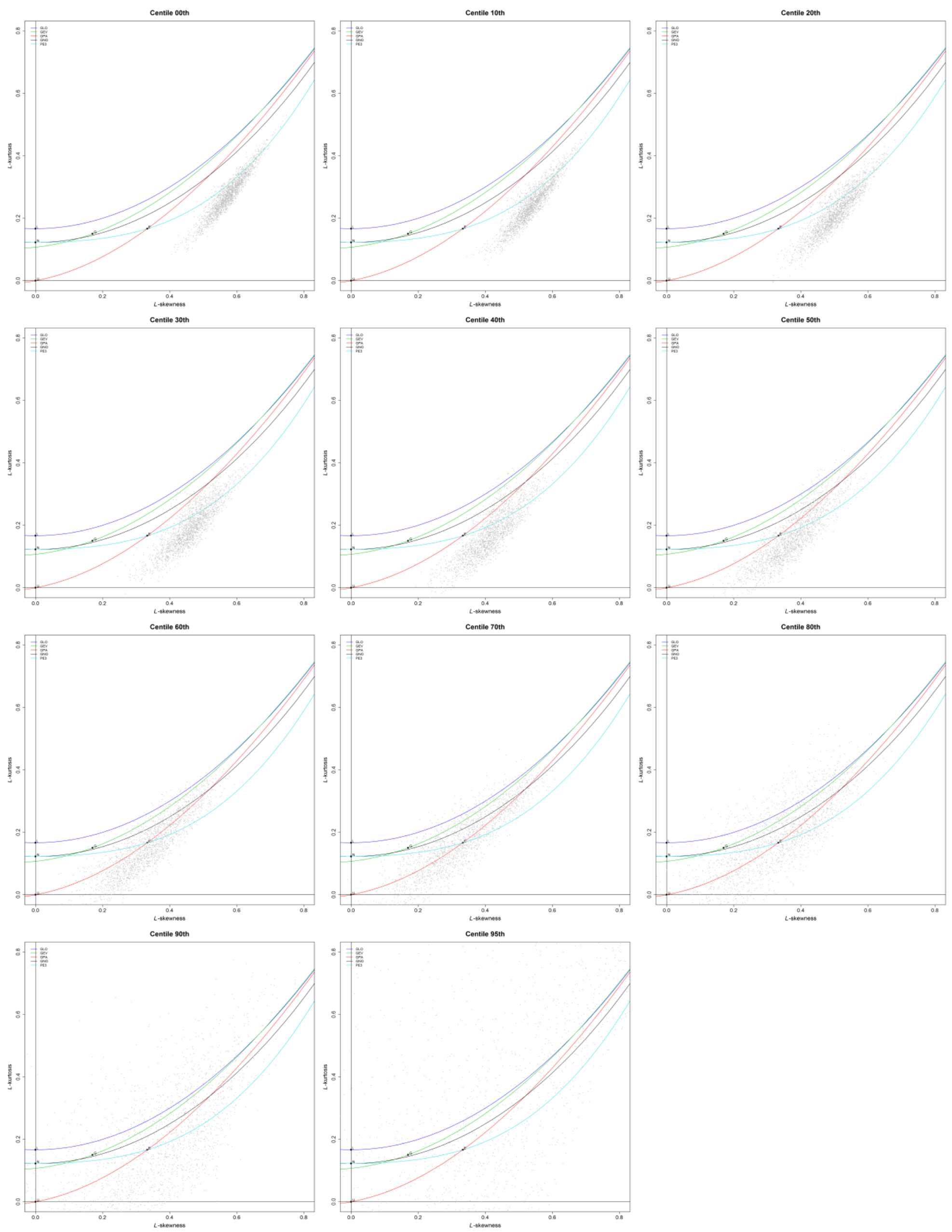

Supplementary Figure 13: L-moment diagrams for the peak-over-threshold series obtained from the 6-month SPI magnitude series 

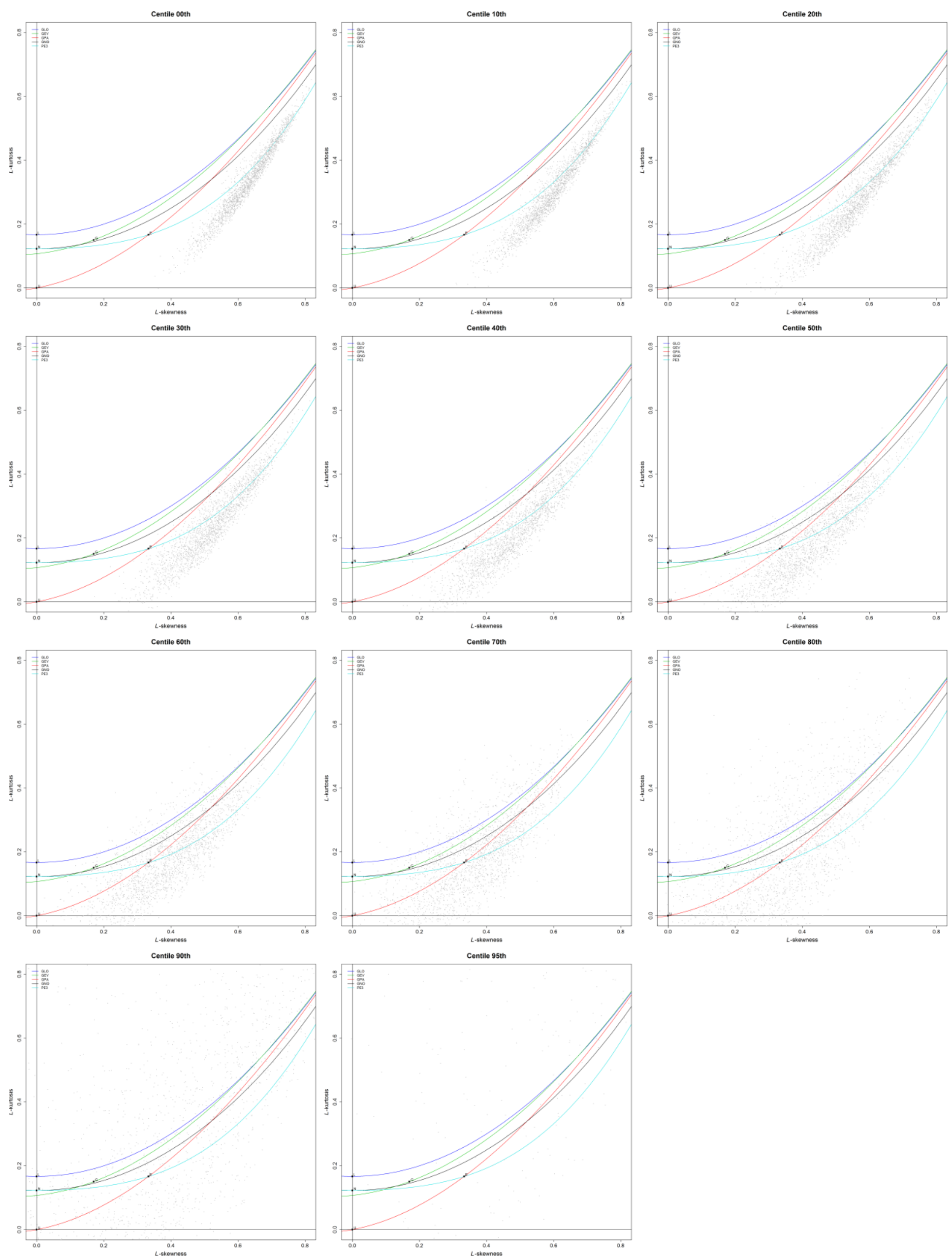

Supplementary Figure 14: L-moment diagrams for the peak-over-threshold series obtained from the 12-month SPI magnitude series 


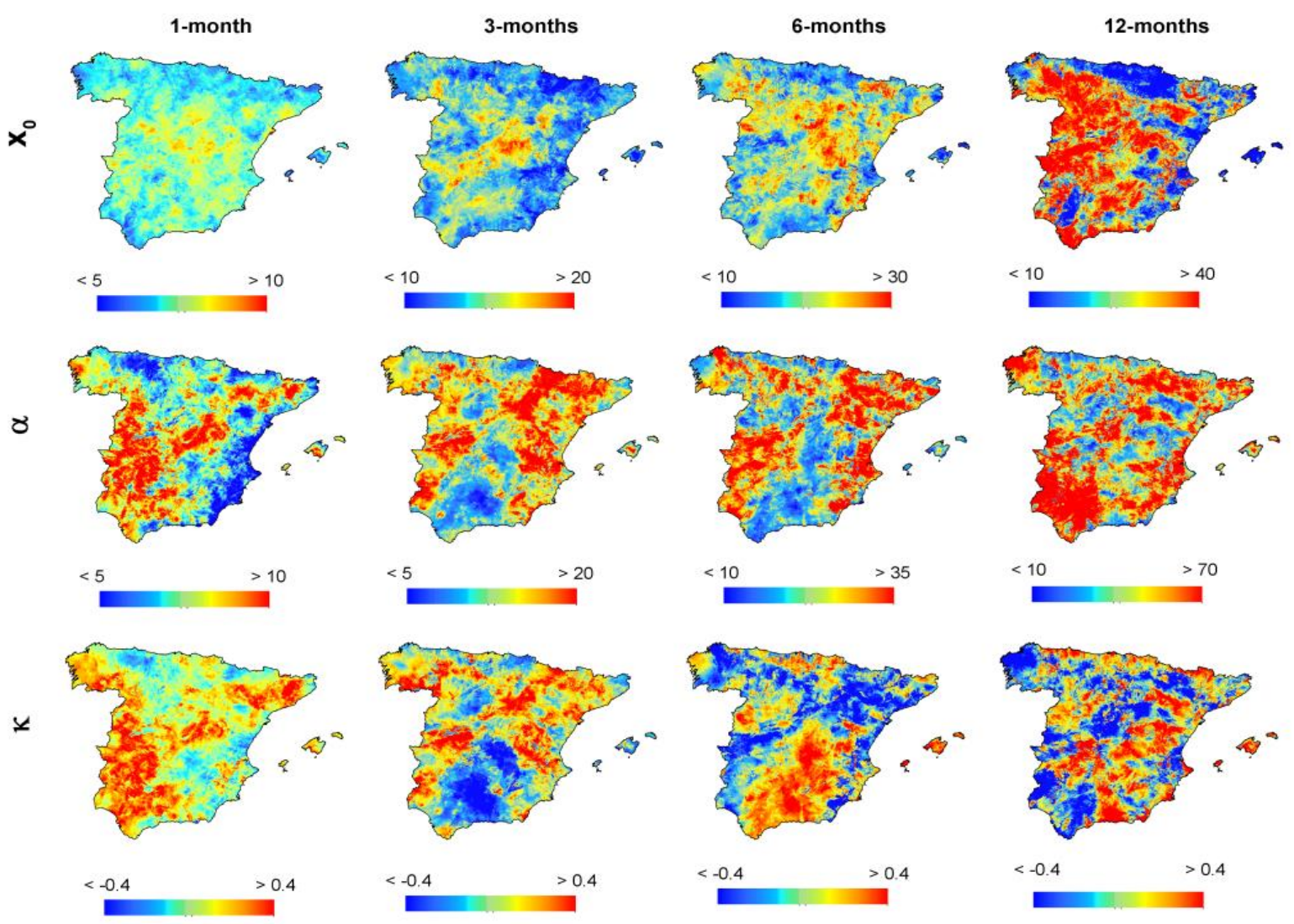

Supplementary Figure 15: Spatial distribution of the parameters of the GP distribution for the SPI magnitude series 

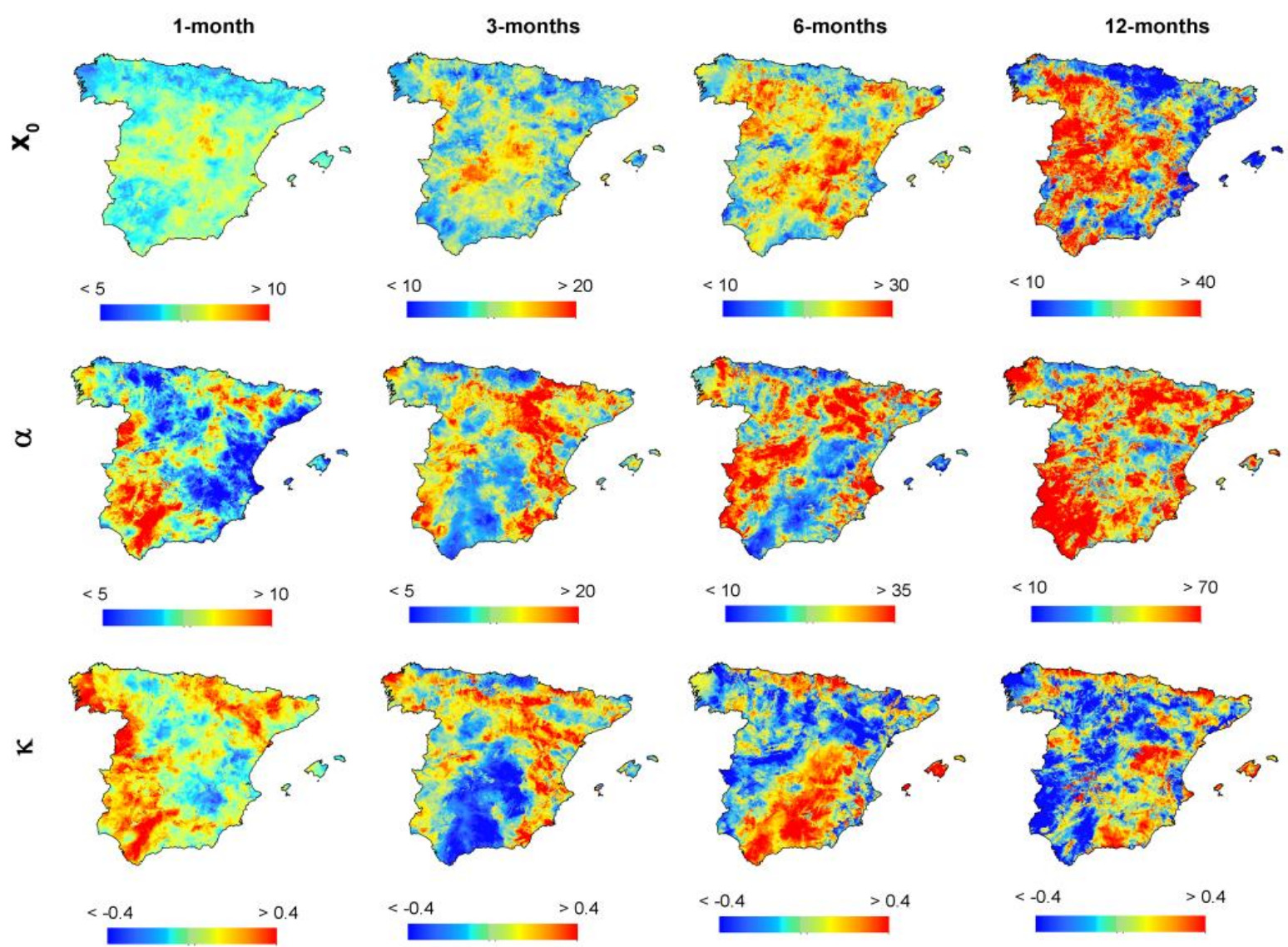

Supplementary Figure 16: Spatial distribution of the parameters of the GP distribution for the SPEI magnitude series 
1 month

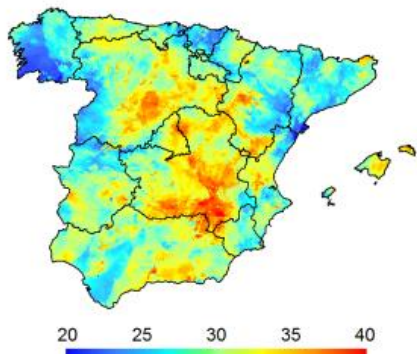

$\begin{array}{lllll}20 & 25 & 30 & 35 & 40\end{array}$
3 months

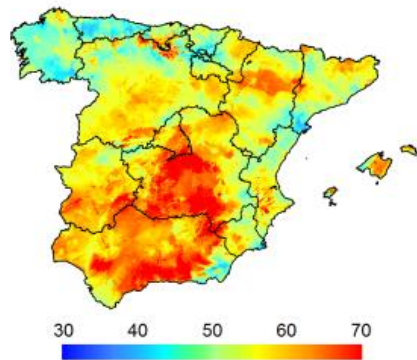

6 months

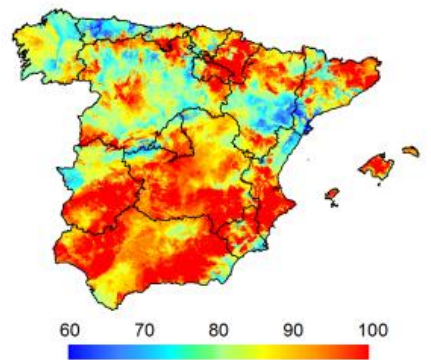

12 months

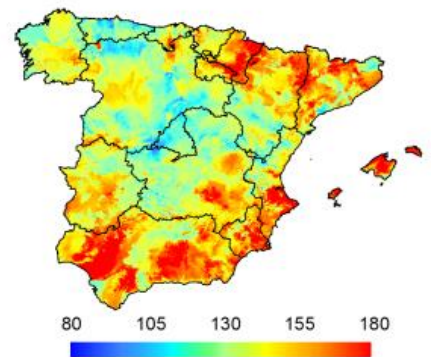

\section{Maximum in 100 years}

1 month

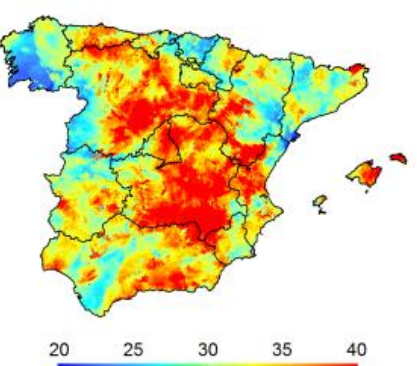

3 months

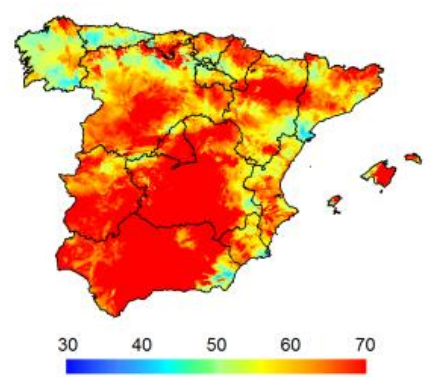

6 months

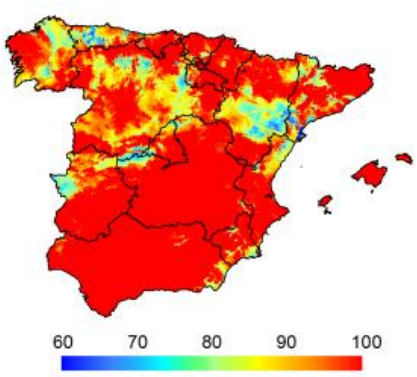

12 months

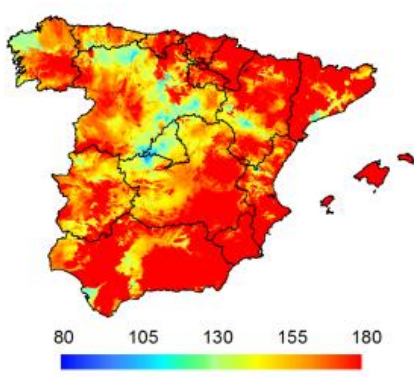

Supplementary Figure 17: Spatial distribution of the maximum drought magnitude (in z-units) from the 1-, 3-, 6- and 12-month SPEI series in a period of $\mathbf{5 0}$ and $\mathbf{1 0 0}$ years. 


\section{Maximum in $\mathbf{5 0}$ years}

1 month

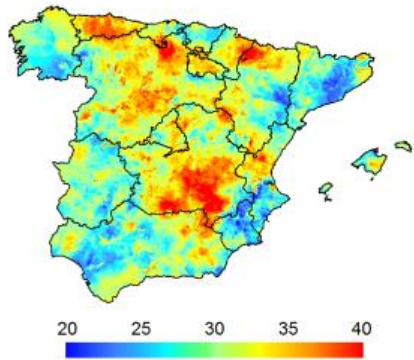

3 months

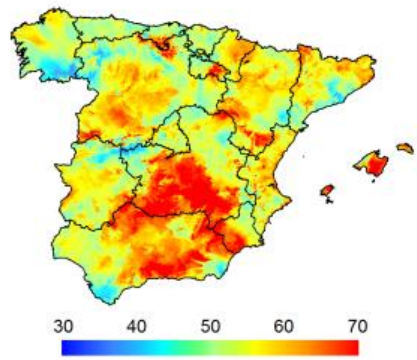

6 months

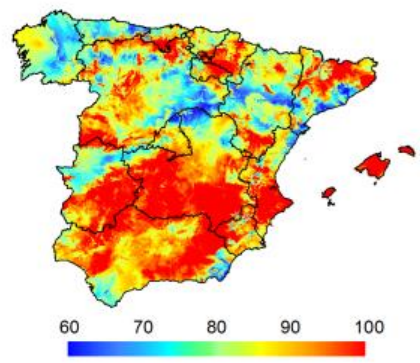

12 months

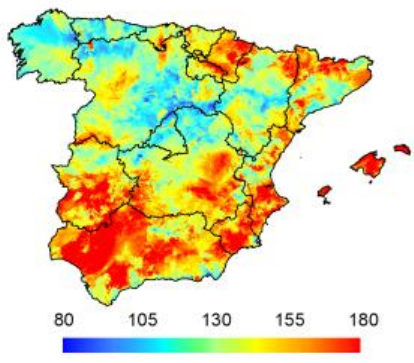

\section{Maximum in 100 years}
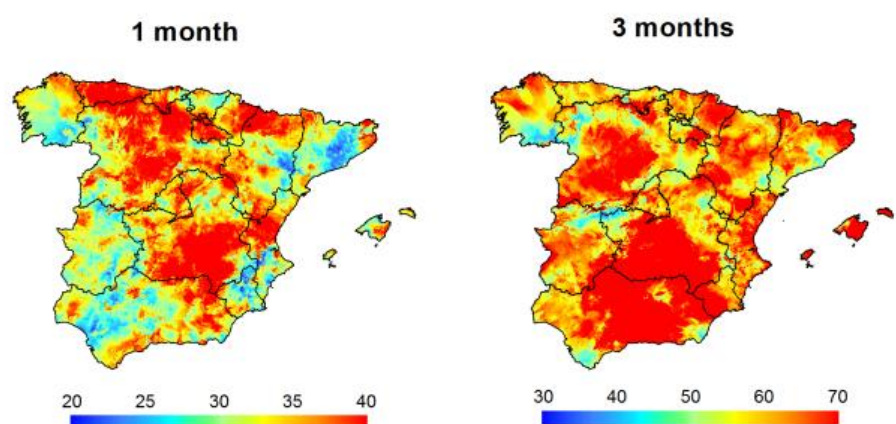

6 months

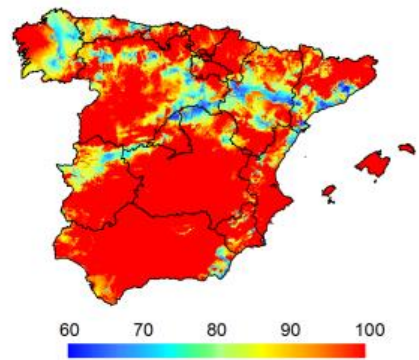

12 months

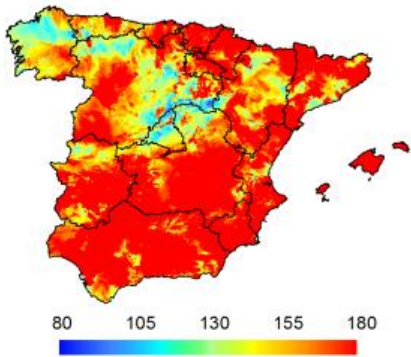

Supplementary Figure 18: Spatial distribution of the maximum drought magnitude (in z-units) from the 1-, 3-, 6- and 12-month SPI series in a period of 50 and 100 years. 

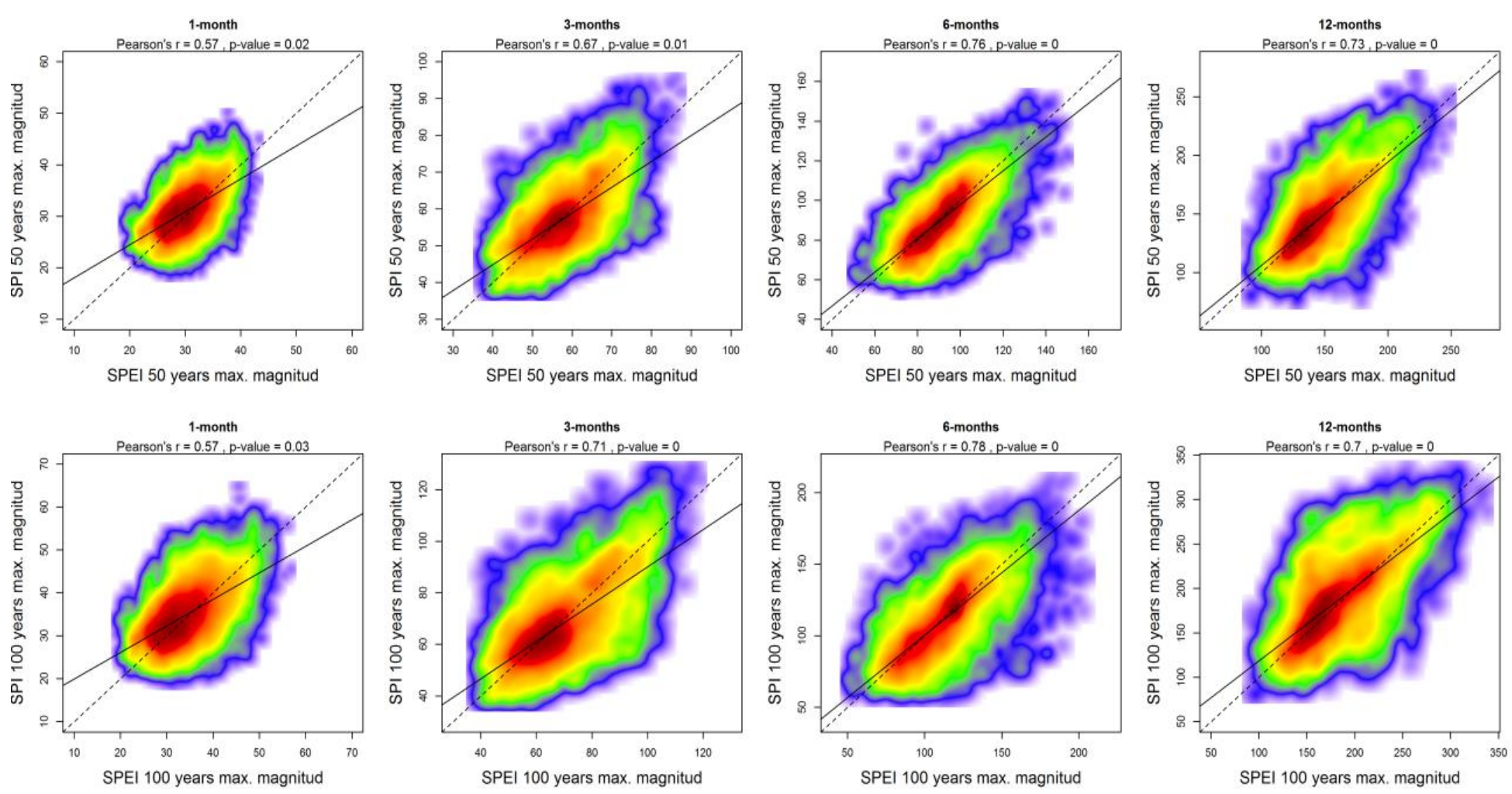

Supplementary Figure 19: Scatterplots showing the relationship between the maximum magnitude (in z-units) expected in a period of 50 and 100 years considering 1-, 3-, 6- and 12- SPEI and the SPI. Colors represent the density of points, with red denoting the highest density. Given the large sample used, the significance of the Pearson's $r$ coefficients was estimated by means of a Montecarlo approach using $10^{3}$ random samples, with each sample containing 30 cases. 